\title{
Effect of Microstructure on the Electrochemical Behavior of Ti-10 Mass\% Mn Alloys in High Chloride Solution \\ Toshiyasu Nishimura
}

\author{
(Submitted September 10, 2015; in revised form November 25, 2015; published online December 30, 2015)
}

\begin{abstract}
The effect of microstructure on the corrosion of heat-treated Ti-10 mass\% Mn alloys was investigated by electrochemical impedance spectroscopy (EIS) in $10 \% \mathrm{NaCl}$ solution of $\mathrm{pH} 0.5$ at $97{ }^{\circ} \mathrm{C}$. Sample of solution heat treatment (ST) had a single $\beta$ phase, and samples subjected to the aging heat treatment at $600{ }^{\circ} \mathrm{C}$ had $\alpha$ phase precipitation in $\beta$ phases. The EIS measurements showed that the corrosion resistance of the aging heat-treated samples showed lower values than ST sample, however, much higher values than pure Ti. Thus, Mn was effective to increase the corrosion resistance of Ti alloys. Laser micrographs of heat-treated samples indicated that $\alpha$ phase was selectively corroded and made the pit after the corrosion test. The transmission electron microscope (TEM)-energy dispersive $x$-ray spectrometry (EDXS) analyses showed that the Mn content was 9 mass $\%$ in the $\beta$ phase and 0.7 mass $\%$ in $\alpha$ phase. Hence, it was understood that less-Mn $\alpha$ phase was selectively corroded in the corrosion test. However, as compared with pure Ti, the aging heat-treated samples showed much higher resistance against the corrosion by the $0.7 \mathrm{mass} \% \mathrm{Mn}$ in $\alpha$ phase. Finally, it was concluded that it was possible to keep the high corrosion resistance for heat-treated Ti-10 mass\% Mn alloy by controlling the microstructure of $\alpha$ phase.
\end{abstract}

Keywords corrosion, EIS, TEM, titanium alloys

\section{Introduction}

Titanium (Ti) alloys are widely used for structural applications, for example, in the chemical plants and the oil production industries. The vast utilization of titanium and its alloys own to their excellent mechanical property and high corrosion resistance (Ref 1). However, Ti is susceptible to the corrosion attack when exposed to environments containing high level acidic solution at elevated temperatures (Ref 2, 3). In order to overcome this defect of $\mathrm{Ti}$, much attention has been paid to improve the corrosion resistance of $\mathrm{Ti}$ by increasing the stability of the surface oxide film. In the case of alloying design, noble metals such as $\mathrm{Pt}, \mathrm{Pd}$, and $\mathrm{Ru}$ were used to increase the corrosion resistance. It was found that those $\mathrm{Ti}$ alloys had good resistance in acidic media (Ref 4-8). However, such elements are rare metal, and, recently, their costs are increasing remarkably. It has been documented that alloying $\mathrm{Ti}$ with sufficient quantities of molybdenum (Mo) provides high corrosion resistance (Ref 9, 10). In our work, Ti-15 mass\% Mo alloy was found to be a highly corrosion-resistant alloy instead of rare metal in high level acidic solution at elevated temperatures (Ref 11, 12).

Recently, $\beta$-phase type Ti alloy is becoming an attractive alloy because it has high specific strengths with excellent strength and high cold deformability. However, the elements of $\beta$-former are very rare and expensive, such as $\mathrm{Nb}, \mathrm{V}$, and $\mathrm{Ta}$. Thus, we have increased the corrosion resistance of Ti alloy by

Toshiyasu Nishimura, National Institute for Materials Science (NIMS), 1-2-1 Sengen, Tsukuba 305-0047, Japan. Contact e-mail: NISHIMURA.Toshiyasu@nims.go.jp. using Mo (Ref 11, 12). However, Mo is also getting rare and expensive element in these days. Thus, we are very much interested in using Manganese $(\mathrm{Mn})$ as a cheap $\beta$-former in alloy design. However, there are few papers which demonstrate the effect of $\mathrm{Mn}$ on the corrosion resistance of $\mathrm{Ti}$ alloy. Moreover, an investigation for the effect of microstructure of metal on corrosion behavior of Ti-Mn alloys has not been reported. In the case of welding, it is important to examine the effect of the microstructure of heat affected zone (HAZ) on the corrosion behavior. Moreover, Ti-Mn alloy can increase the strength by the precipitation of $\alpha$ phase in $\beta$ base metal. Hence, the present work is focused to assess the corrosion behavior of heat-treated Ti-10 mass \% Mn alloys in high chloride and low $\mathrm{pH}$ condition. The stability of the passive film and breakdown behavior was investigated by open circuit potential (OCP) along with electrochemical impedance spectroscopy (EIS) in $10 \% \mathrm{NaCl}$ solution of $0.5 \mathrm{pH}$ at $97{ }^{\circ} \mathrm{C}$. The microstructure of alloy was examined by field emission scanning electron microscopy (FE-SEM) and high-resolution transmission electron microscopy (HR-TEM) in combination with an energy dispersive $\mathrm{X}$-ray (EDAX) analysis. Finally, the effect of microstructure on the corrosion of heat-treated Ti-10 mass $\%$ Mn alloy was discussed in order to keep the high corrosion resistance by controlling the microstructure of alloys.

\section{Experimental Method}

\subsection{Materials Treatment}

Ti alloy containing 10 mass $\%$ of $\mathrm{Mn}$ was made by arc melting process at a vacuum level of $10^{-5}$ atom in the present investigation. Different types of heat treatment procedures were carried out over the Ti-10\% Mn alloy in order to research the effect of metal microstructures on the corrosion. The various heat treatments and the designations assigned to the specimen are provided in the Table 1. All samples were conducted the 
solution treatment (ST) at $900{ }^{\circ} \mathrm{C}$ for $1 \mathrm{~h}$ and then water quenched (WQ). NC0 sample was subjected to ST only. NC1 sample was subjected to the aging heat treatment at $700{ }^{\circ} \mathrm{C}$ for $1 \mathrm{~h}$. NC2 and NC3 samples were subjected to the aging heat treatment at $600{ }^{\circ} \mathrm{C}$ for 10 and $1 \mathrm{~h}$, respectively. In order to examine the microstructure of heat-treated alloys, surface of all the specimens was mechanically polished to a final level of 0.3 $\mu \mathrm{m}$ alumina powder and, then, etched in $\mathrm{H}_{2} \mathrm{O}$ with nitric acid and hydrofluoric acid (100:3:2 in volume ratio) without the control of the temperature.

\subsection{Electrochemical Measurements}

The specimens were cut into 1.0-1.0-0.2 $\mathrm{cm}$ for the electrochemical studies. These specimens were covered with epoxy resin so as to expose only one face to the test solution. The surface to be exposed was polished with $\mathrm{SiC}$ emery paper up to 1500 grit and used for Electrochemical Impedance

\section{Table 1 Heat treatment conditions of Ti-10\% Mn alloy}

\begin{tabular}{lcc}
\hline No & Samples & Treatment \\
\hline 1 & $\mathrm{NC} 0$ & $900{ }^{\circ} \mathrm{C}-1 \mathrm{~h}, \mathrm{WQ}$ (ST) \\
2 & $\mathrm{NC} 1$ & $900{ }^{\circ} \mathrm{C}-1 \mathrm{~h}, \mathrm{WQ}$ (ST) \\
& $700{ }^{\circ} \mathrm{C}-1 \mathrm{~h}, \mathrm{WQ}$ \\
3 & $\mathrm{NC} 2$ & $900{ }^{\circ} \mathrm{C}-1 \mathrm{~h}, \mathrm{WQ}$ (ST) \\
& $600{ }^{\circ} \mathrm{C}-1 \mathrm{~h}, \mathrm{WQ}$ \\
4 & $\mathrm{NC} 3$ & $900{ }^{\circ} \mathrm{C}-1 \mathrm{~h}, \mathrm{WQ}$ (ST) \\
& $600{ }^{\circ} \mathrm{C}-1 \mathrm{~h}, \mathrm{WQ}$ \\
& \\
\hline \multirow{2}{*}{ ST, solution treatment; WQ, water quench } \\
\hline
\end{tabular}

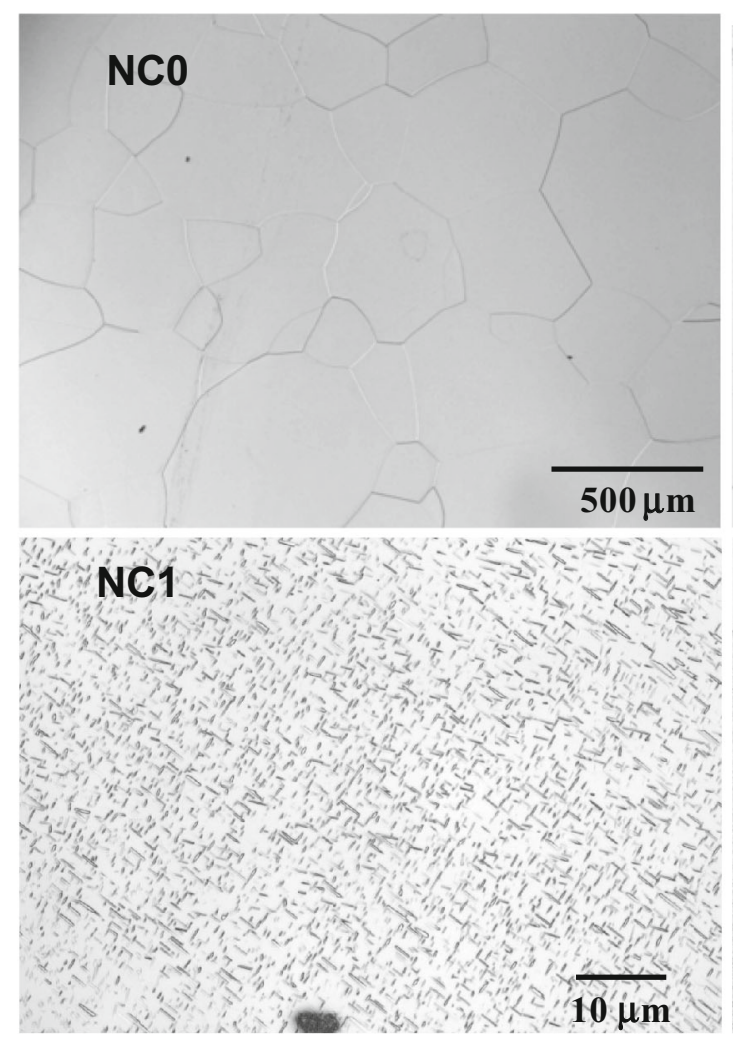

Spectroscopic (EIS; HZ3000, Hokuto-denko) measurements. The electrochemical cell consisted of heat-treated Ti-10\% Mn alloy as a working electrode, platinum $(\mathrm{Pt})$ as a counter electrode, and saturated calomel electrode (SCE) as a reference electrode. The measurements were conducted in $10 \% \mathrm{NaCl}$ adjusted to $\mathrm{pH}$ values of 0.5 by $\mathrm{HCl}$ in deaerated (Ar) condition at $97{ }^{\circ} \mathrm{C}$ kept by the oil bath. In order to reduce the temperature, the cooling system was used, where the water was cooled through the condenser. Moreover, in order to keep the solution condition constantly, the deaerated solutions were used to eliminate the effect of Oxygen. The test specimens were set in the test solution for 30 minutes to attain steady state of the potential. Then, all the EIS measurements were measured by applying a amplitude of $10 \mathrm{mV}$ and by scanning the frequency ranging from $20 \mathrm{KHz}$ to $3 \mathrm{mHz}$. In order to examine the breakdown of passive film on Ti-10\% Mn alloy, EIS measurements were conducted for the specimens immersed in high chloride and low $\mathrm{pH}$ solution for several days at OCP conditions.

\subsection{Surface Characterization}

The heat-treated Ti-10\% Mn alloys were analyzed using Laser microscope instrument (VK-8500, Keyence) to investigate the surface profile after corrosion in the test solution. The precipitated phases of Ti-10\% Mn were analyzed using SEM instrument (JSM-5900LV, JEOL) with an applied voltage of 30 $\mathrm{kV}$ in combination with an EDXS. TEM (JEM-ARM200F, JEOL) observations were carried out to examine the nanostructure of alloy on samples which were prepared by ion beam milling. By using an EDXS, the chemical composition around the precipitated $\alpha$ phase was measured.
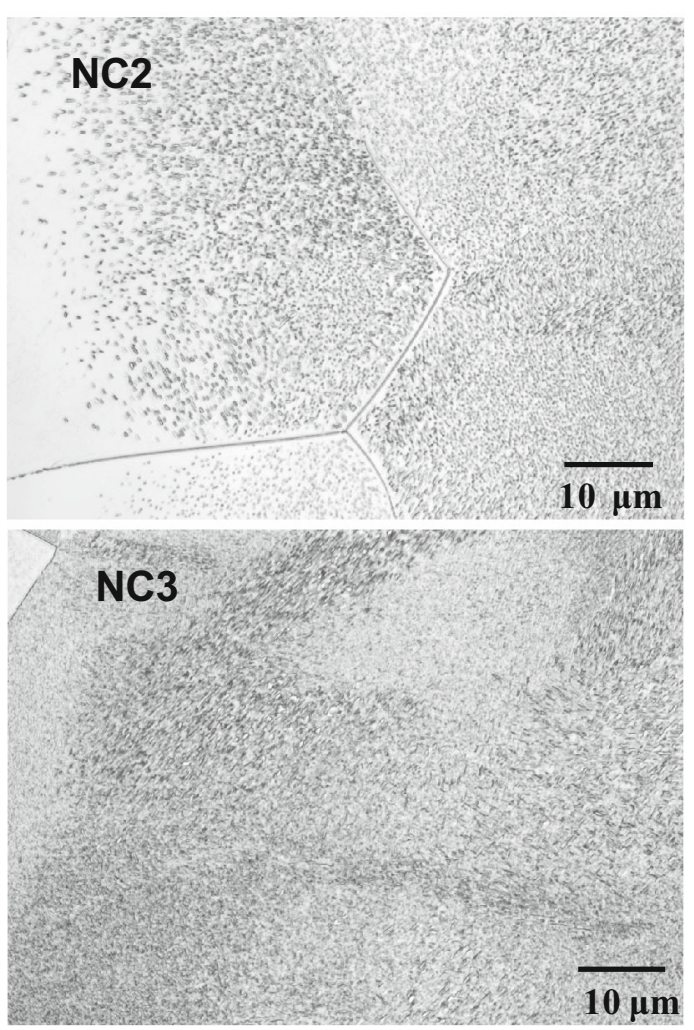

Fig. 1 Microstructure of heat-treated Ti-10\% Mn alloys (heat-treated conditions are shown in Table 1) 


\section{Results and Discussion}

\subsection{Microstructures of Heat-Treated Ti-10 Mass\% Mn Alloys}

Figure 1 shows the microstructures of Ti-10\% Mn samples after their respective aging heat treatments. As for $\mathrm{NC} 0$ sample

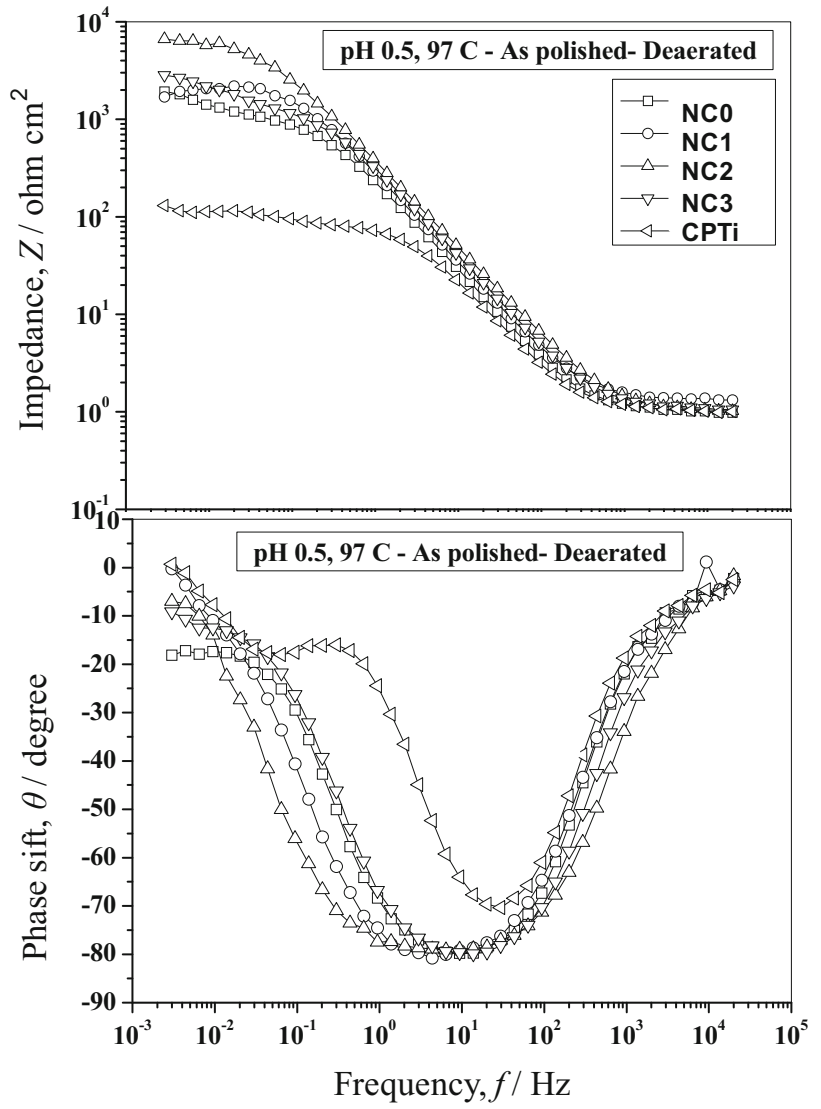

Fig. 2 EIS behaviors of heat-treated Ti-10\% Mn alloys (NC 0-3) and pure $\mathrm{Ti}(\mathrm{CPTi})$ as polished surface in $10 \% \mathrm{NaCl}$ solution of $\mathrm{pH}$ 0.5 at $97{ }^{\circ} \mathrm{C}$

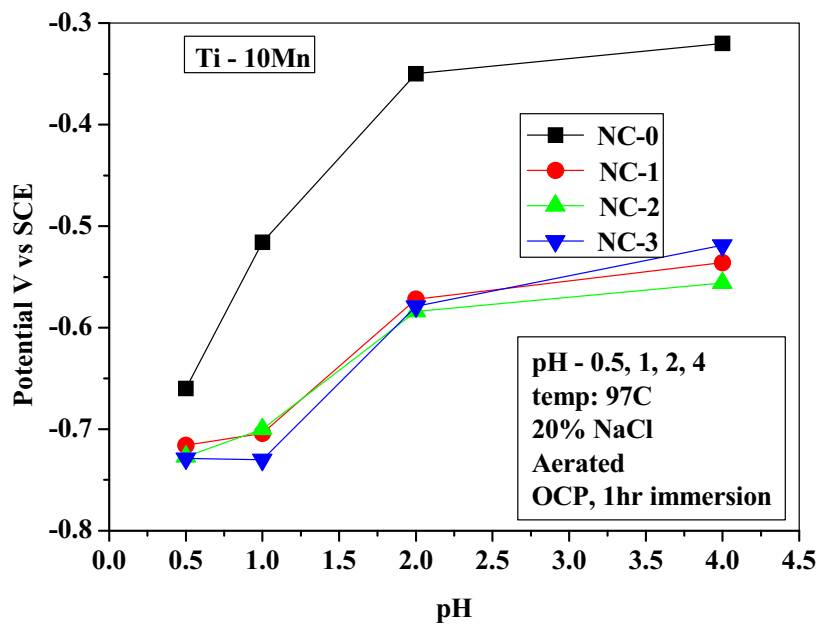

Fig. 3 Open circuit potential (OCP) of heat-treated Ti-10\% Mn alloys. After $1 \mathrm{~h}$ in $10 \% \mathrm{NaCl}$ of various $\mathrm{pH}$ at $97{ }^{\circ} \mathrm{C}$ which was conducted only ST, the microstructure consists of relatively large grains of a single $\beta$ phase with an average size of $200 \mu \mathrm{m}$. However, in case of NC1, NC2, and NC3 samples which were subjected to the aging heat treatment at 700 or $600{ }^{\circ} \mathrm{C}, \alpha$ phase precipitated as needle shape in each of the $\beta$ grain.

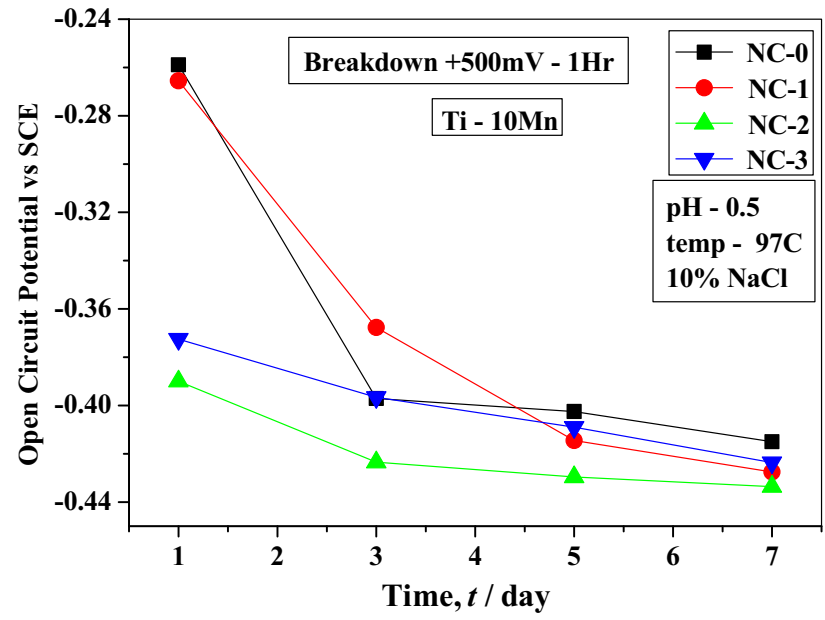

Fig. 4 Potential decays of heat-treated Ti-10\% Mn alloys in 10\% $\mathrm{NaCl}$ of $\mathrm{pH} 0.5$ at $97^{\circ} \mathrm{C}$
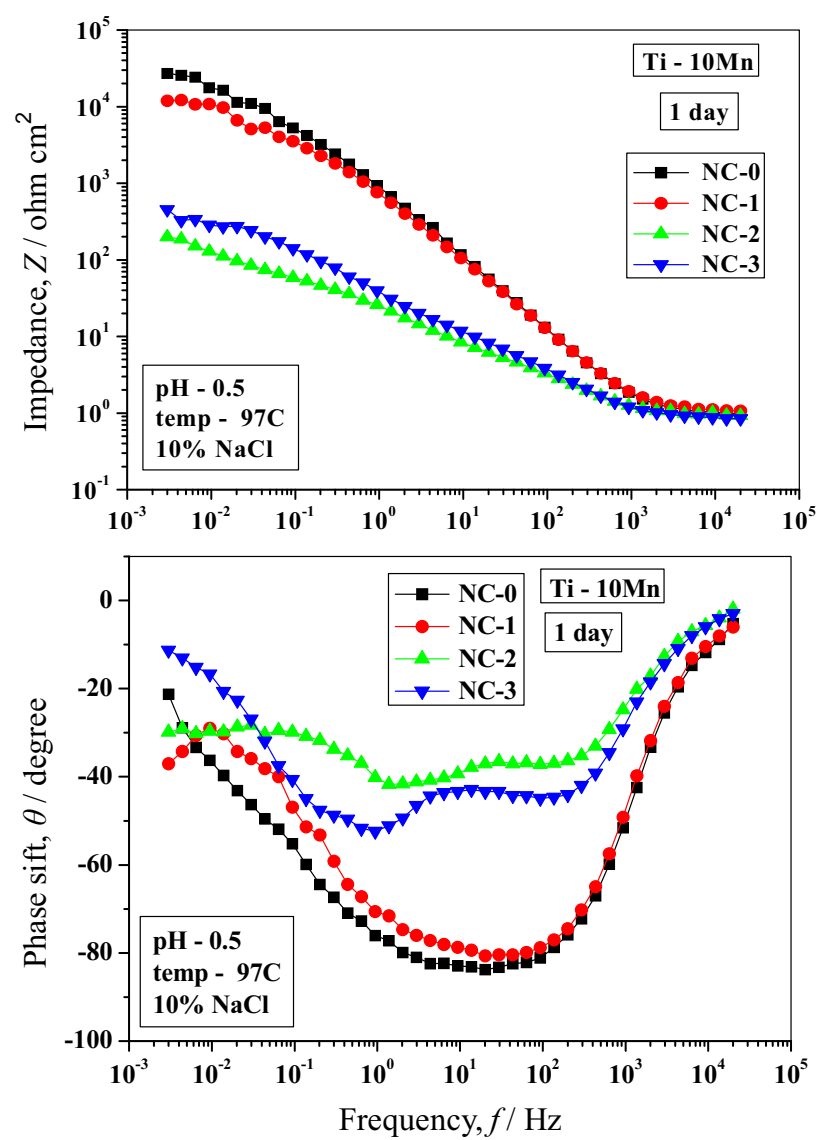

Fig. 5 EIS behaviors of heat-treated Ti-10\% Mn alloys after 1 day in $10 \% \mathrm{NaCl}$ of $\mathrm{pH} 0.5$ at $97{ }^{\circ} \mathrm{C}$ 


\subsection{Electrochemical Impedance Spectroscopic (EIS) Measurement}

In order to confirm the influence of $\mathrm{Mn}$ and microstructures on the resistance against corrosion, EIS measurements were carried out for heat-treated Ti-10\% Mn alloys. Samples as polished condition were conducted EIS measurement in a deaerated $10 \% \mathrm{NaCl}$ at a $\mathrm{pH}$ of 0.5 at $97{ }^{\circ} \mathrm{C}$. Moreover, the pure $\mathrm{Ti}$ (CP-Ti) was examined as a comparison. The EIS spectra are shown in Fig. 2. The each EIS spectrum is composed of two resistances and one capacitance component in Fig. 2. NC 0-3 samples exhibit higher impedance values $\left(R_{\mathrm{t}}\right)$ of $10^{3}-10^{4} \Omega \mathrm{cm}^{2}$ at lowest frequency region. These results show that all samples of alloys are passivated, and show high corrosion resistance even in a severe condition of $10 \% \mathrm{NaCl}$ at a $\mathrm{pH}$ of 0.5 at $97{ }^{\circ} \mathrm{C}$. Thus, the equivalent circuit has the solution resistance $\left(R_{\mathrm{sol}}\right)$, the oxide film resistance $\left(R_{\mathrm{film}}\right)$, and the film capacitance $\left(C_{\text {film }}\right)$ in an EIS spectrum. Moreover, the EIS spectra show that microstructures of alloys slightly affect the corrosion resistance, although all samples can keep the passive condition. On the other hand, pure Ti shows the lowest value of $120 \Omega \mathrm{cm}^{2}$ at lowest frequency region, which shows the active dissolution of base metal. In this way, heat-treated Ti$10 \%$ Mn shows much higher resistance against the corrosion than pure Ti. It was shown that Mn was effective to increase the corrosion resistance of $\mathrm{Ti}$ alloy in high chloride and low $\mathrm{pH}$ condition.
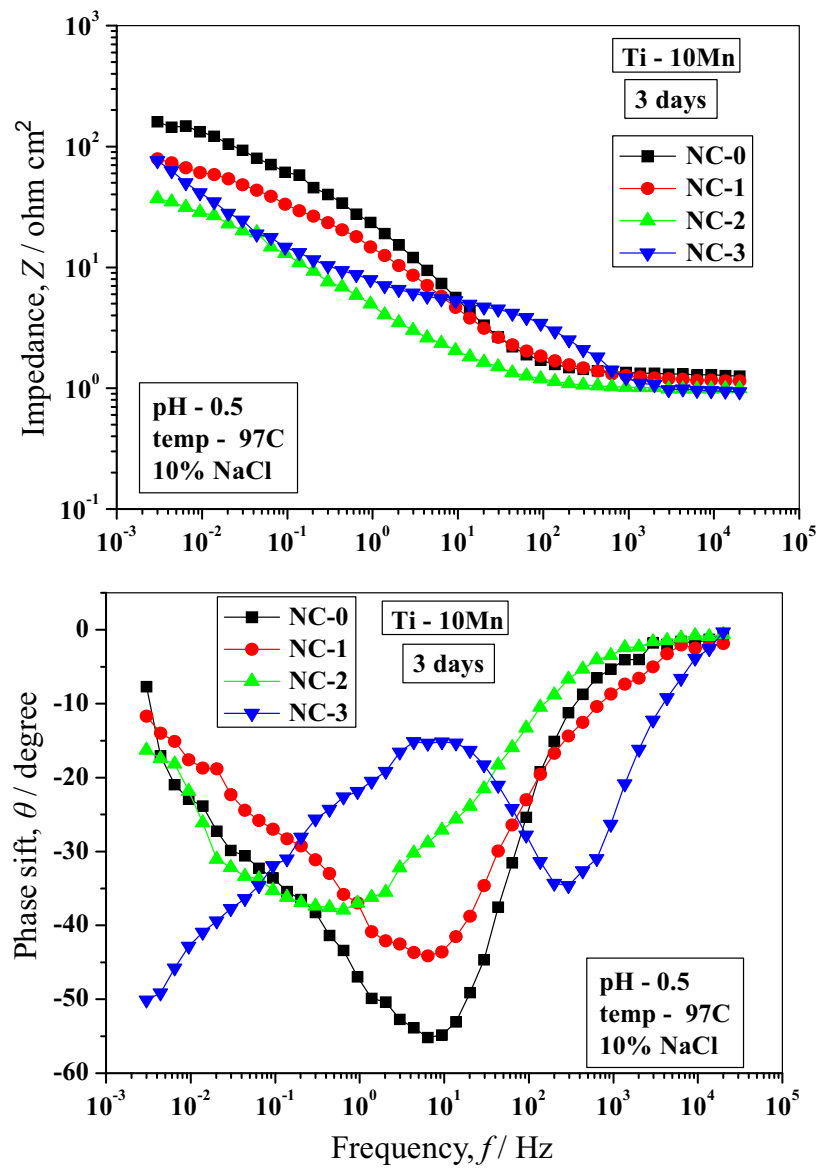

Fig. 6 EIS behaviors of heat-treated Ti-10\% Mn alloys after 3 days in $10 \% \mathrm{NaCl}$ of $\mathrm{pH} 0.5$ at $97{ }^{\circ} \mathrm{C}$
Figure 3 shows OCP of heat-treated Ti-10\% Mn alloys after $1 \mathrm{~h}$ in $10 \% \mathrm{NaCl}$ of various $\mathrm{pH}$ at $97{ }^{\circ} \mathrm{C}$. As compared with the heat-treated samples of NC1-NC3, ST sample of NC0 shows higher potential in each $\mathrm{pH}$ condition. Although the higher
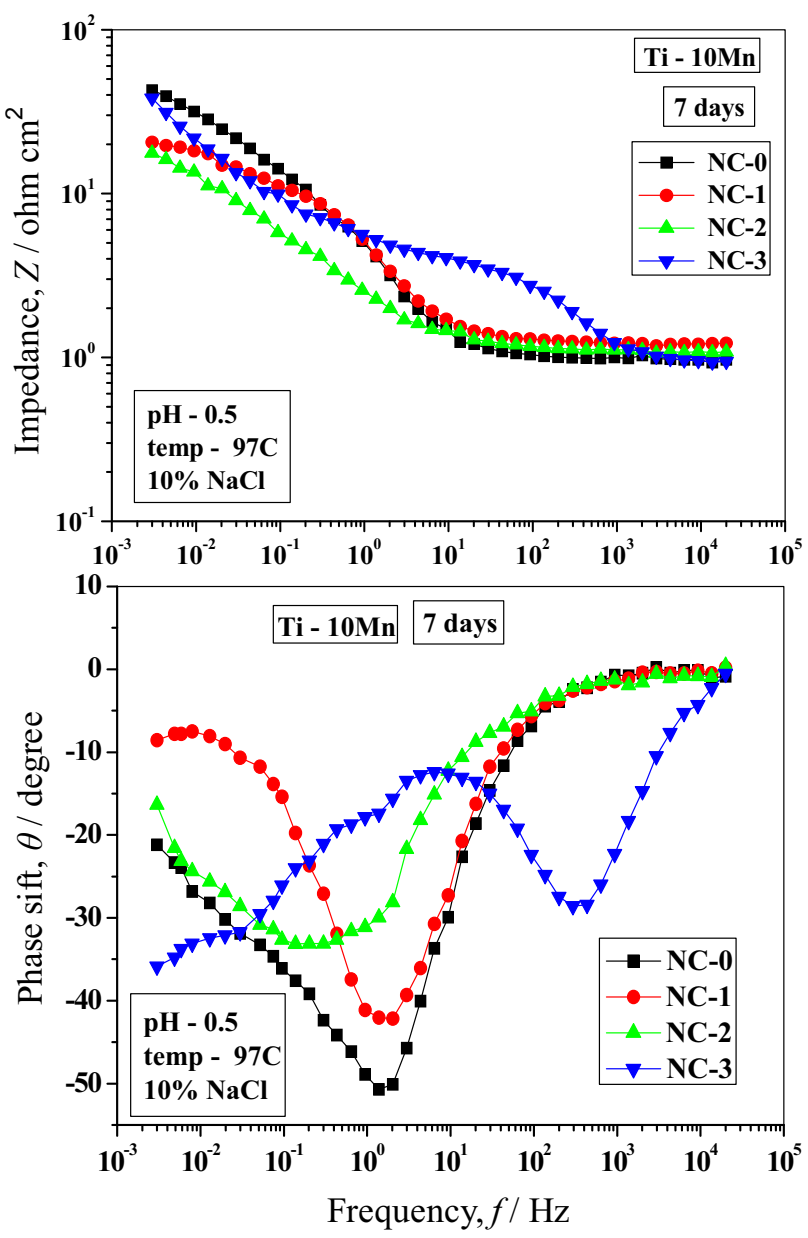

Fig. 7 EIS behaviors of heat-treated Ti-10\% Mn alloys after 7 days in $10 \% \mathrm{NaCl}$ of $\mathrm{pH} 0.5$ at $97{ }^{\circ} \mathrm{C}$

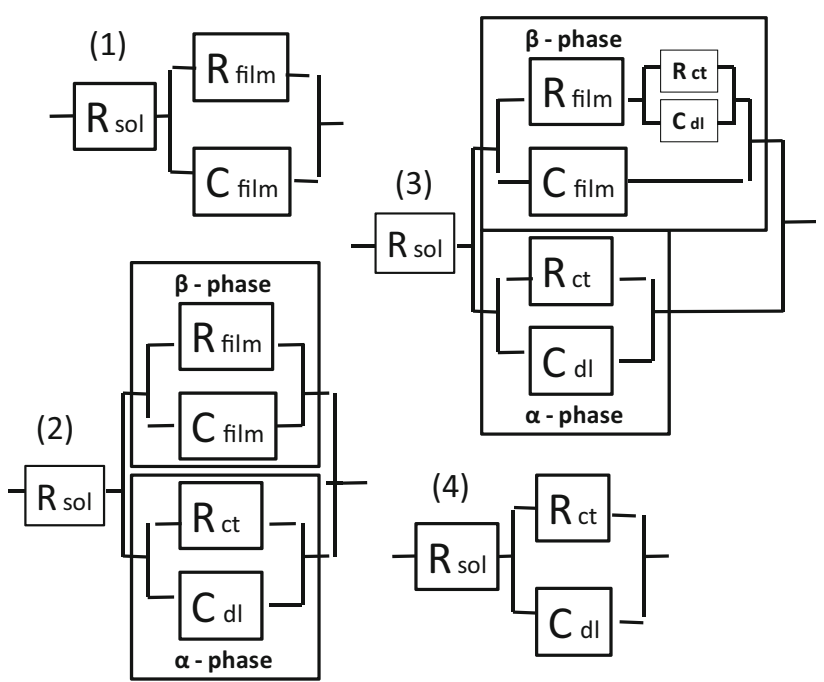

Fig. 8 Equivalent circuit for the corrosion of heat-treated Ti-10\% Mn alloys in $10 \% \mathrm{NaCl}$ of $\mathrm{pH} 0.5$ at $97{ }^{\circ} \mathrm{C}$ 
OCP does not necessarily mean higher corrosion resistance, however, OCP was widely changed from higher potential region of $-0.3 \mathrm{~V}$ to lower one less than $-0.7 \mathrm{~V}$, which showed the change from the passive to active state according to the $\mathrm{pH}$ of the solution. Thus, the sample which has no $\alpha$ phase demonstrates the higher corrosion resistance. In another words, $\alpha$ phase decreases the corrosion resistance of Ti-10\% Mn alloy in high chloride and low $\mathrm{pH}$ condition.

It is important to investigate the stability of the passive film over longer duration for the Ti alloys which have 2 nd phases. Hence, all the samples were passivated at $+500 \mathrm{mV}$ for $1 \mathrm{~h}$, and

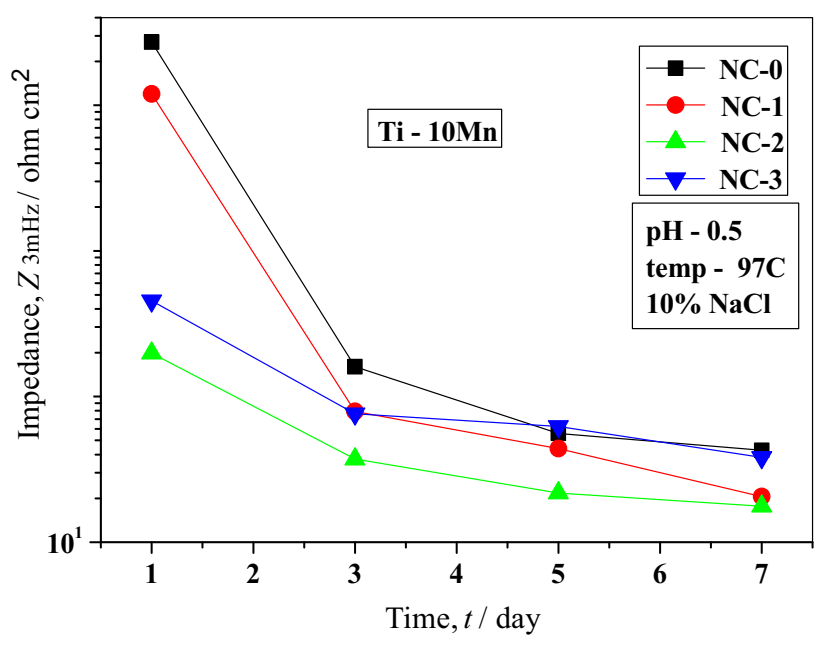

Fig. 9 Change in impedance values at $3 \mathrm{mHz}(Z 3 \mathrm{mHz})$ for heattreated $\mathrm{Ti}-10 \% \mathrm{Mn}$ alloys in $10 \% \mathrm{NaCl}$ of $\mathrm{pH} 0.5$ at $97{ }^{\circ} \mathrm{C}$ then kept at its OCP in the above test solution for 7 days. The passive region was thought to be in the potential range of -400 to $1000 \mathrm{mV}$ from Fig. 3. Thus, in order to set the passive restate completely, the potential was kept at $+500 \mathrm{mV}$ in this study. The OCP was monitored during the experiment, and EIS measurements were carried after 1st, 3rd, and 7th day of immersion. Figure 4 shows the OCP decay of samples for 7 days after the passivation for $1 \mathrm{~h}$ in test solution. It is found that $\mathrm{NC} 2$ and NC3 samples show low OCP value of -0.39 and $-0.37 \mathrm{~V}$, respectively, after 1 day of immersion. However, NC0 of ST and NC1 samples show higher value after 1 day. This behavior indicates that the ST sample of only $\beta$ phase shows higher resistance against corrosion compared to the others. After 5 days, all OCPs of samples show low value from -0.43 to $-0.40 \mathrm{~V}$, which indicates the active dissolution of metal. Thus, heat-treated Ti-10\% Mn shows the start of the depassivation after 5 days.

Figure 5, 6, and 7 show the EIS spectra of heat-treated Ti$10 \% \mathrm{Mn}$ alloys after 1 to 7 days in $10 \% \mathrm{NaCl}$ of $\mathrm{pH} 0.5$ at $97{ }^{\circ} \mathrm{C}$. In Fig. 5, EIS spectra of $\mathrm{NC0}$ and $\mathrm{NC} 1$ sample show one capacitance and very high impedance values of $10^{4} \Omega \mathrm{cm}^{2}$ at low-frequency region, which indicates the passive condition. This behavior is corresponding to the equivalent circuit (1) in Fig. 8. On the other hand, EIS spectra of NC2 and NC3 show 2 capacitances and low impedance values of 200 to $600 \Omega \mathrm{cm}^{2}$ at low-frequency region. This behavior shows the start of the dissolution of $\alpha$ phase in the passivated $\beta$ phase. Thus, this result is thought corresponding to the equivalent circuit (2) in Fig. 8. This circuit contains the $R_{\mathrm{ct}}$ (charge transfer resistance) and $C_{\mathrm{dl}}$ (double layer capacitance) of $\alpha$ phase in the parallel of $R_{\text {film }}$ and $C_{\text {film }}$ in $\beta$ phase. Here, two capacitances are mainly corresponding to the $C_{\text {film }}$ in $\beta$ phase and $C_{\mathrm{dl}}$ in $\alpha$ phase.
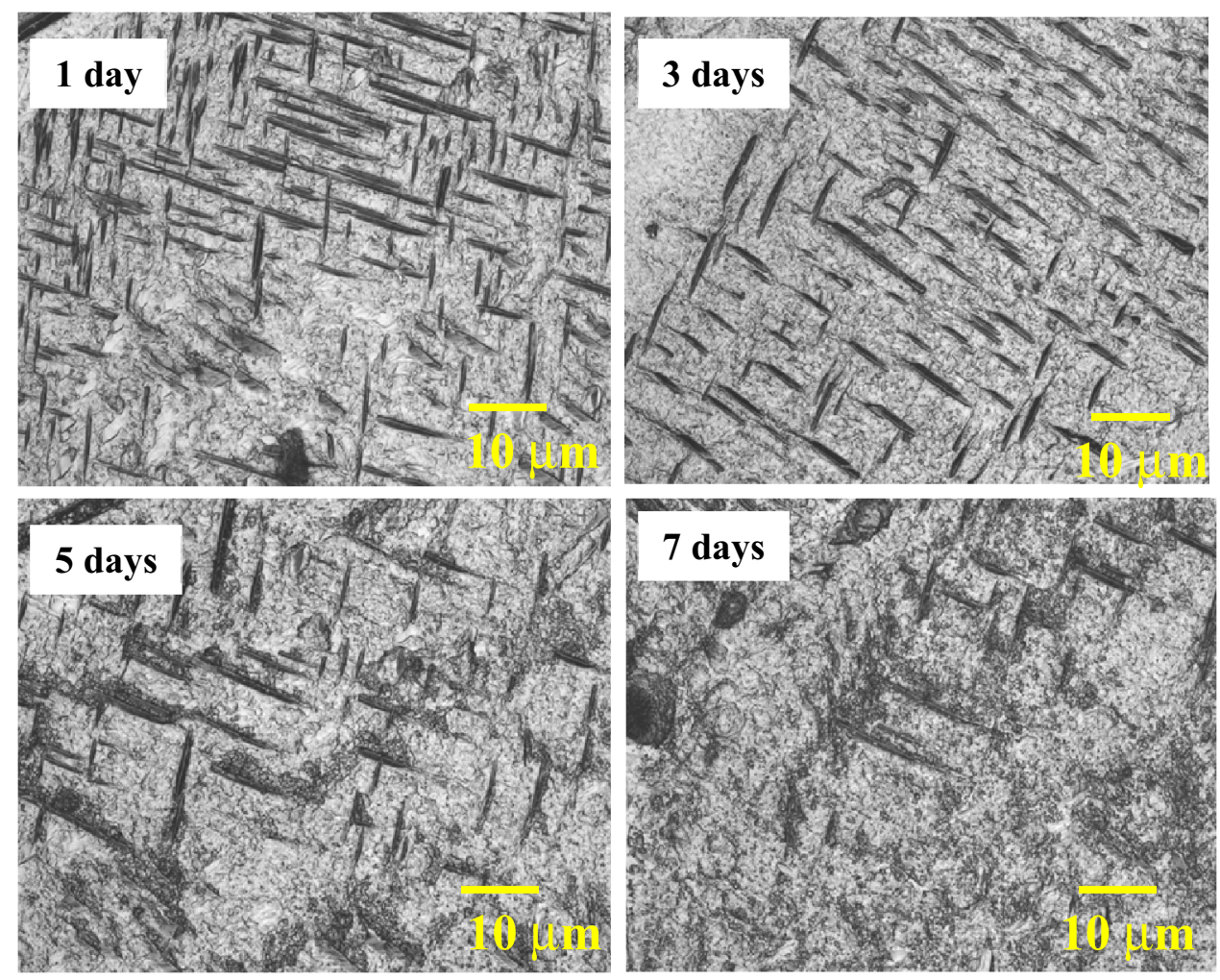

Fig. 10 Laser micrograph profile of heat-treated Ti-10\% Mn alloy (NC3) after 7 days immersion in $10 \% \mathrm{NaCl}$ of $\mathrm{pH} 0.5$ at $97{ }^{\circ} \mathrm{C}$ 
Figure 6 shows the EIS spectra of heat-treated Ti-10\% Mn alloys after 3 days in test solution. All EIS spectra show low impedance values of 40 to $200 \Omega \mathrm{cm}^{2}$ at low-frequency region. This behavior is thought to show the start of the active dissolution of $\beta$ phase. Thus, this result is thought corresponding to the equivalent circuit (3) in Fig. 8. This circuit contains additionally the $R_{\mathrm{ct}}$ and $C_{\mathrm{dl}}$ of the active dissolution of $\beta$ phase in the circuit (2). Here, as the passive film of $\beta$ phase is thought still existing at the surface, the circuit contains $R_{\text {film }}$ and $C_{\text {film }}$ in $\beta$ phase. However, $C_{\text {film }}$ and $C_{\mathrm{dl}}$ of $\beta$ phase are difficult to be distinguished clearly in the EIS spectrum by the complicated corrosion in actual environment.

Figure 7 shows the EIS spectra of heat-treated Ti-10\% Mn alloys after 7 days in test solution. All EIS spectra show very low impedance values of 20 to $50 \Omega \mathrm{cm}^{2}$ at low-frequency region. This behavior is thought that all surface of the sample is conducting the anodic dissolution. Thus, this result is thought corresponding to the equivalent circuit (4) in Fig. 8. This circuit shows only the $R_{\mathrm{ct}}$ and $C_{\mathrm{dl}}$ of the surface. Only NC3 sample shows the capacitance at the middle-frequency region. Maybe it is corresponding to the corrosion product on the surface; however, it needs more examination. In this way, EIS spectra during the corrosion test are explained by the equivalent circuits in Fig. 8.

Figure 9 shows the impedance $\left(Z_{3 \mathrm{mHz}}\right)$ at $3 \mathrm{mHz}$ in EIS spectra in the corrosion test on different days in Fig. 5, 6, 7, and 8. $Z_{3 \mathrm{mHz}}$ value for $\mathrm{NC0}$ sample as $\mathrm{ST}$ and $\mathrm{NC1}$ is found to be more than $10^{4} \Omega \mathrm{cm}^{2}$ at $1 \mathrm{st}$ day, which is much higher than other heat-treated samples. This result confirms that the passive film formed over $\mathrm{NCO}$ as ST is stable even in highly acidic chloride solutions at high temperature. On the contrary, NC2 and NC3 samples reveal lower $Z_{3 \mathrm{mHz}}$ values of 200 and $500 \Omega$ $\mathrm{cm}^{2}$ after 1 day of immersion. After 3 days immersion, $Z_{3 \mathrm{mHz}}$ values for all samples are reducing to the low level of active dissolution. After 7 days, among the samples, the highest value of $Z_{3 \mathrm{mHz}}$ belongs to $\mathrm{NC} 0$, and low values are shown by $\mathrm{NC} 2$ and NC3. Moreover, $Z_{3 \mathrm{mHz}}$ is thought corresponding to the corrosion resistance $\left(R_{\mathrm{t}}\right)$ of these samples. Thus, these results indicate that the corrosion resistance $\left(R_{\mathrm{t}}\right)$ is decreased by the 2nd phase in the metal structure of Ti-10\% Mn alloys in highly acidic chloride solution. In the case of $\mathrm{NC} 1$ aged at $700{ }^{\circ} \mathrm{C}$, as the amount of $\alpha$ phase is less than NC2 and NC3 aged at $600{ }^{\circ} \mathrm{C}, R_{\mathrm{t}}$ of $\mathrm{NCl}$ is thought higher in the test condition.

\subsection{Surface Characterization After Corrosion for Heat- Treated Ti-10 Mass\% Mn Alloys}

Figure 10 shows the laser micrographs on the surfaces of heat-treated $\mathrm{Ti}-10 \% \mathrm{Mn}$ sample of NC3 after different days of immersion in $10 \% \mathrm{NaCl}$ of $\mathrm{pH} 0.5$ at $97{ }^{\circ} \mathrm{C}$. The surface on NC3 sample is slightly affected and shows the needle-shaped dissolution in the test solution after 1 day. This behavior is thought related with the selective dissolution of $\alpha$ phase in the metal structure. In the case of 3 and 5 days, the width of the needle-shaped dissolution is increasing. Thus, the dissolution of $\alpha$ phase is increasing as a test time. After 7 days, the needleshaped dissolution is not clear. This behavior is thought related to the dissolution of base metal of $\beta$ phase. Then, the surface of sample is uniformly corroded, and the trace of the needle shape is vanishing.

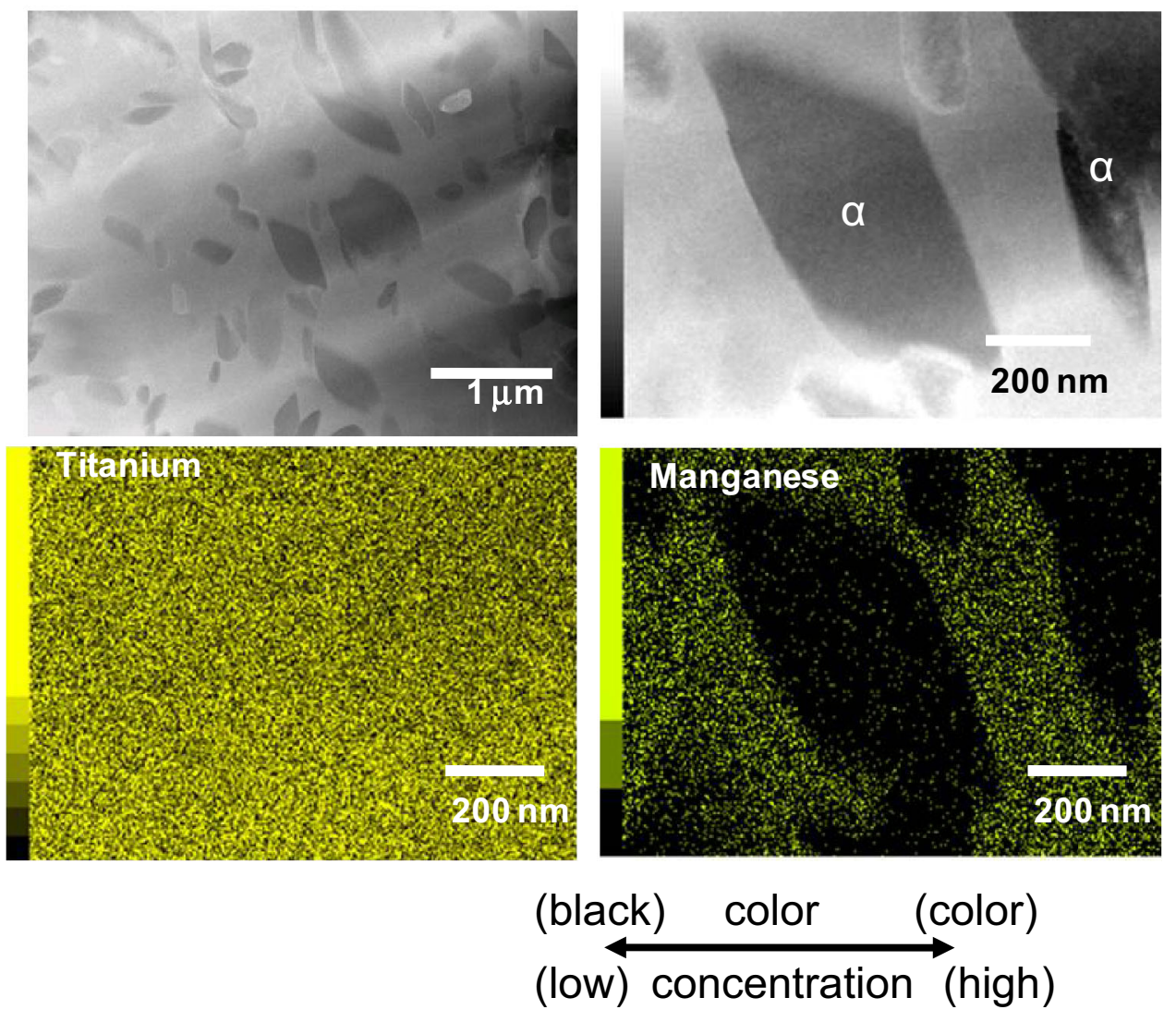

Fig. 11 SEM-EDAX mapping analysis of Ti and Mn for heat-treated Ti-10\% Mn alloy (NC3) 


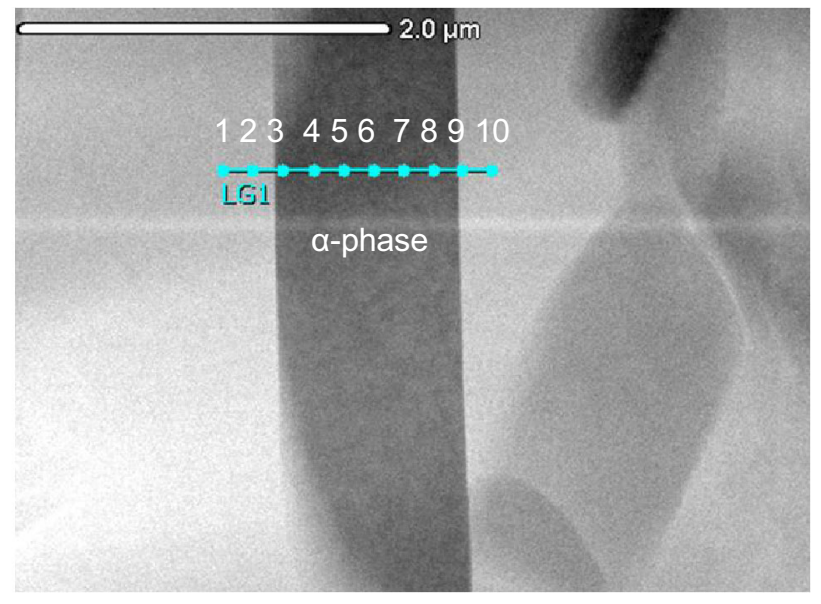

Fig. 12 Spot positions by TEM-EDAX analysis of heat-treated Ti$10 \%$ Mn alloys (NC3)

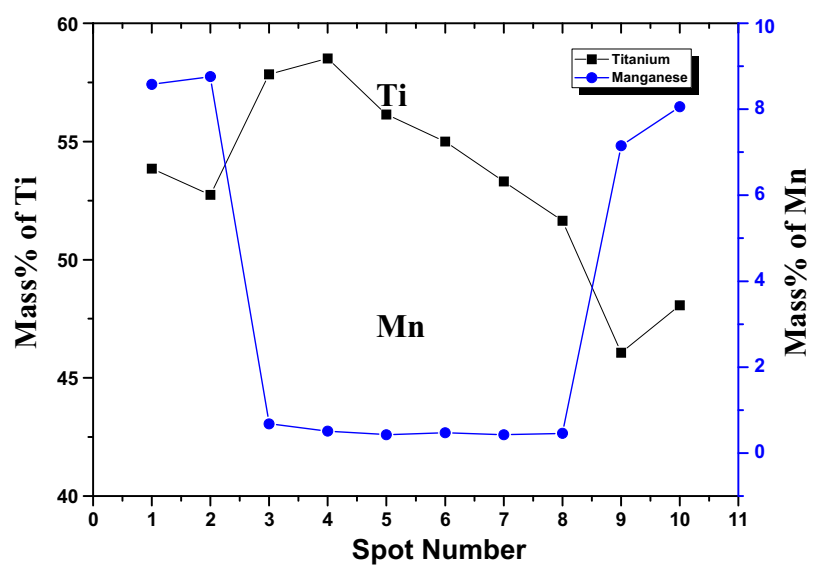

Fig. 13 TEM-EDAX line profile (LG1) of Mn and Ti on heat-treated $\mathrm{Ti}-10 \%$ Mn alloy (NC3) corresponding to Fig. 12

In order to confirm the details of the precipitated phase in the grains and at the boundaries, SEM and TEM with corresponding EDXS were use to identify the form and elemental composition of it. SEM-EDAX mapping analysis of heat-treated NC3 sample was carried out and is shown in Fig. 11. The mapping shows the elemental composition of Ti and $\mathrm{Mn}$ around $\alpha$ phase. Although the distribution of Ti is not clear, however, it is found that the content of $\mathrm{Mn}$ in $\alpha$ phase is less than that in base metal.

TEM bright-field images are shown for NC3 sample in Fig. 12. It is apparent that the shape of $\alpha$ phase is like the needle. Here, the micrograph depicts the spot position of analysis, and typical EDXS spectra are shown in Fig. 13. Figure 13 shows the line profile of the EDXS analysis around $\alpha$ phases corresponding to LG1 line in Fig. 12. The subsequent graph in Fig. 13 shows the elemental composition of Ti and Mn in mass $\%$ corresponding to the each spots in Fig. 12. This figure clearly indicates a drastic drop in the mass $\%$ of $\mathrm{Mn}$ according to the change from $\beta$ to $\alpha$ phase. Actually from the EDX results, it is found that there are $\beta$ phase of 9 mass $\%$ and $\alpha$ phase of 0.7 mass $\%$ Mn forms a metal structure in NC3. Thus, less-Mn $\alpha$ phase was thought selectively dissolved in a corrosive solution in the above experiment.

\subsection{Corrosion Mechanism for Heat-Treated Ti-10 Mass\% Mn Alloys}

From the surface analysis, it was found that heat-treated Ti$10 \%$ Mn alloys had Mn-rich $\beta$ phase and Mn-less $\alpha$ phase in a metal structure. Thus, as micro-galvanic couple is composed of the Mn-less $\alpha$ phase and Mn-rich $\beta$ phase, the active part of $\alpha$ phase is highly susceptible to corrosion. Hence, in Fig. 10, corrosion preferentially was occurred at the position where $\alpha$ phase was precipitated in $\mathrm{NC} 2$ and $\mathrm{NC} 3$. In case of $\mathrm{NC} 0$ as ST which has only a $\beta$ phase, the susceptibility to corrosion is totally less than other samples. As the single $\beta$ phase has rich $\mathrm{Mn}$ throughout the sample, it can prevent the corrosion. Compared with pure Ti, the samples which have $\alpha$ phases in Ti$10 \% \mathrm{Mn}$ alloys show higher resistance against the corrosion. This behavior is explained by the fact that $\alpha$ phase contains 0.7 mass \% Mn which improves the corrosion resistance against the pure Ti. Moreover, in the case of long duration in test solution, Mn-rich $\beta$ phase is remained longer time at the surface after the selective dissolution of $\alpha$ phase, and then, it is kept at the high resistance against the corrosion. These results are demonstrated by the EIS behavior, laser microscopic studies, and the surface analysis. In this way, we are thought to be able to keep the high corrosion resistance for heat-treated Ti-10\% Mn alloy by controlling the microstructure of $\alpha$ phase.

\section{Conclusions}

The effect of microstructure on the corrosion of heat-treated Ti-10 mass $\%$ Mn alloys was investigated by EIS in $10 \% \mathrm{NaCl}$ solution of $\mathrm{pH} 0.5$ at $97^{\circ} \mathrm{C}$. Moreover, TEM analysis was conducted to identify the relationship between microstructure and corrosion behavior of heat-treated Ti-10 mass\% Mn alloys. The results are summarized as follows:

1. SEM micrographs confirmed that the relatively large grains of a single $\beta$ phase were detected for the sample (NC0) as ST, and both $\alpha$ and $\beta$ phases were observed for other samples which were subjected aging heat treatment at 700 and $600{ }^{\circ} \mathrm{C}$.

2. The EIS measurements showed that the corrosion resistance $\left(R_{\mathrm{t}}\right)$ of alloys decreased with immersion time against the corrosion at high temperature. The corrosion resistance of the aging heat-treated samples of Ti- $10 \%$ Mn alloys showed lower values than ST sample, however, much higher values than pure Ti.

3. Laser micrographs of heat-treated alloys showed that $\alpha$ phase was selectively corroded and the width of the needle-shaped dissolution is increasing as corrosion test time.

4. The TEM-EDXS analyses showed that the Mn content was high of 9 mass $\%$ in the $\beta$ phase compared to 0.7 mass $\%$ in $\alpha$ phase. Hence, less-Mn $\alpha$ phase was selectively corroded in the corrosion test. Thus, ST sample of only $\beta$ phase showed the highest resistance, and aging heat-treated samples containing $\alpha$ phases $(0.7$ mass $\%$ $\mathrm{Mn}$ ) showed higher resistance than pure $\mathrm{Ti}$ in the corrosion test.

5. Finally, it was concluded that it was possible to keep the high corrosion resistance for heat-treated Ti- $10 \% \mathrm{Mn}$ alloy by controlling the microstructure of $\alpha$ phase. 


\section{Acknowledgments}

The authors acknowledge the helpful comment and the assistance of Dr. X H Min and Dr. V Raman on this work.

\section{Open Access}

This article is distributed under the terms of the Creative Commons Attribution 4.0 International License (http://creativecommons.org/ licenses/by/4.0/), which permits unrestricted use, distribution, and reproduction in any medium, provided you give appropriate credit to the original author(s) and the source, provide a link to the Creative Commons license, and indicate if changes were made.

\section{References}

1. P.G. Pound, Corrosion Behavior of Metallic Materials in Biomedical Applications. I. Ti and Its Alloys, Corros. Rev., 2014, 32, p 1-20

2. B. Vicentini, D. Sinigaglia, and G. Taccani, Crevice Corrosion of Titanium. Behaviour of Galvanic Cell Between Shielded and Unshielded Titanium in Sulphuric Acid, Corros. Sci., 1975, 15, p 479-483

3. L.A. Yao, F.X. Gan, Y.X. Zhoa, C.L. Yao, and J.L. Bear, Microelectrode Monitoring the Crevice Corrosion of Titanium, Corrosion, 1991, 47, p $420-425$
4. S.Y. Yu, C.W. Brodrick, M.P. Ryan, and J.R. Scully, A New Activation Process for a Zr-Based Alloy as a Negative Electrode for Ni/MH Electric Vehicle Batteries, J Electrochem. Soc., 1999, 146, p 44294438

5. S.Y. Yu, J.R. Scully, and C.M. Vitus, Influence of Niobium and Zirconium Alloying Additions on the Anodic Dissolution Behavior of Activated Titanium in $\mathrm{HCl}$ Solutions, J Electrochem. Soc., 2001, 148, p B68-B78

6. D.G. Kolman and J.R. Scully, Electrochemistry and Passivity of a Ti-15Mo-3Nb-3Al Beta-Titanium Alloy in Ambient Temperature Aqueous Chloride Solutions, J Electrochem. Soc., 1993, 140, p 2771-2779

7. C.S. Brossia and G.A. Cragnolino, Effect of Palladium on the Corrosion Behavior of Titanium, Corros. Sci., 2004, 46, p 1693-1711

8. R.S. Glass and Y.K. Hong, Transpassive Behaviour of Titaniummolybdenum Alloys in $1 \mathrm{NH}_{2} \mathrm{SO}_{4}$, Electrochim. Acta, 1984, 29, p 1465-1470

9. N.D. Tomashov, G.P. Chernova, Y.S. Ruscol, and G.A. Ayuyan, The Passivation of Alloys on Titanium Bases, Electrochim. Acta, 1974, 19, p $159-163$

10. N.D. Tomashov, Factors of Control and Metal Protection Against Corrosion, Corros. Sci., 1961, 1, p 77-87

11. T. Nishimura, Corrosion Resistance of Molybdenum-Containing Titanium Alloy for Overpack in Simulating Underground Environment, $J$. Nucl. Mater., 2009, 385, p 495-503

12. S. Tamilselvi, T. Nishimura, X.H. Min, and K. Tsuzaki, The Effect of Microstructure on Corrosion of Molybdenum-Bearing Titanium Alloys in High Chloride and Acidic Solution at High Temperature, Mater. Trans., 2009, 50, p 2545-2551 